\title{
The Activation of Residual Dormant Follicles by Human Chorionic Gonadotropin (HCG) in Vivo: a Novel Treatment for Premature Ovarian Insufficiency
}

\section{Xiao Chen}

The Fourth Affiliated Hospital of Zhejiang University School of Medicine

Keda Yu

Jinhua Polytechnic School of Medicine

Hong Liu

Temple University

\section{Chen Chen}

Temple University

\section{Yuanyuan Yu}

The Fourth Affiliated Hospital of Zhejiang University School of Medicine

Yingying $\mathrm{Hu}$

The Fourth Affiliated Hospital of Zhejiang University School of Medicine

\section{Youjiang Li}

The Fourth Affiliated Hospital of Zhejiang University School of Medicine

\section{Jian xu ( $\nabla$ xuj@zju.edu.cn )}

The Fourth Affiliated Hospital of Zhejiang University School of Medicine

\section{Research Article}

Keywords: Human chorionic gonadotropin, residual dormant follicles, premature ovarian insufficiency, assisted reproductive technology, embryo

Posted Date: January 13th, 2022

DOI: https://doi.org/10.21203/rs.3.rs-1241620/v1

License: (c) (i) This work is licensed under a Creative Commons Attribution 4.0 International License. Read Full License 


\section{Abstract}

\section{Background}

With the influence of factors such as ovarian surgery, high-dose radiotherapy and chemotherapy, environmental degradation, and bad living habits, the occurrence of premature ovarian insufficiency $(\mathrm{POI})$ is getting younger and younger, and many young women's ovaries have entered the aging stage earlier. While many studies have investigated the patients with $\mathrm{POI}$, which is still a challenge in reproductive medicine as the treatments available now are not ideal. POI patients have varying amounts of residual dormant follicles in the ovaries. Therefore, it is critical to further our understanding of primordial follicle activation in order to treat.This study aimed to investigate the activation of residual follicles in POI patients with injection of HCG, whether they could obtain embryos and become pregnant.

\section{Methods}

Four patients with POI were pretreated with dehydroepiandrosterone, Coenzyme Q10, estrogen and medroxyprogesterone. The prescribed amounts of estrogen and medroxyprogesterone were adjusted to maintain the level of FSH at $₫ 15 \mathrm{mlU} / \mathrm{ml}$ and the level of $\mathrm{LH} \otimes 10 \mathrm{mlU} / \mathrm{ml}$. When the treatments failed to induce the appearance of follicles after 3 months, the patients received treatment with 10000 IU of HCG.

\section{Results}

The residual dormant follicles in POI patients can be activated using our approach to obtain embryos and conceive by injection of HCG.

\section{Conclusions}

POI patients may conceive their own genetic children by activating dormant follicles in vivo. These findings may represent a new simple and feasible solution for the treatment of patients with POI to conceive their own genetic children.

\section{Introduction}

With the influence of factors such as ovarian surgery, high-dose radiotherapy and chemotherapy, environmental degradation, and bad living habits, the occurrence of $\mathrm{POI}$ is getting younger and younger, and many young women's ovaries have entered the aging stage earlier. POI is a disease in which the ovarian follicles rapidly decay resulting in low numbers of residual follicles in women before the age of 40 years (1). Indeed, in these patients, the progressive reduction in ovarian reserve due to early loss of primordial follicles eventually leads to $\mathrm{POI}$. $\mathrm{POI}$ is associated with hypoestrogenism and the loss of residual follicles, both of which lead to menstrual abnormalities, pregnancy failures, and decreased health-related quality of life. The current diagnostic criteria for POI from the European Society of Human Reproduction and Embryology (ESHRE) diagnostic include amenorrhoea or oligomenorrhoea for at least four months and increased follicle-stimulating hormone (FSH) levels $>25 \mathrm{IU} / \mathrm{I}$ measured on two occasions (with a four-week interval) (2).

POI patients have varying amounts of residual dormant follicles in the ovaries. When the number of residual follicles declines below a specific threshold ( $<1000$ follicles), they can no longer be activated and follicle development becomes arrested leading to anovulation and amenorrhea (3). Currently, there are a lack of effective treatments for infertility that can increase the rate of conception in POI patients except for oocyte donation in which patients do not 
conceive their own genetic children. Reproductive medicine continues to develop potential therapeutics to allow POI patients to conceive with their own oocytes using approaches to reactivate the ovaries by rescuing dormant follicles or generating functional oocytes in vitro.

The in vitro activation (IVA) of follicles followed by autologous transplantation has enabled POI patients to successfully give birth $(4,5)$ but follicular growth was not observed until one year after transplantation of the ovaries. Recent studies have demonstrated ovarian rejuvenation following the injection of platelet-rich plasma (PRP) or stem cells into artificial gametes and ovaries, using ovarian transplantation, and also with mitochondrial replacement therapy (6). Whilst these infertility treatments may improve the probability of successful birth, they are expensive and the precise mechanisms underpinning their effects remain to be fully understood. Currently, no studies have reported on the activation of residual dormant follicles in vivo.

The injection of human chorionic gonadotropin (HCG) on trigger day induces a surge in luteinizing hormone (LH) to promote the maturation of oocytes and ovulation. The administration of HCG might trigger the resumption of meiosis and nuclear maturation of immature oocytes.(7). Introducing HCG into mammalian and human eggs in vitro has been shown to promote oocyte maturation and improve developmental potential (7-10). These studies have demonstrated the important role of HCG in the development and maturation of follicles. Recently, we developed a simple and feasible new infertility treatment that has enabled four POI patients to obtain viable embryos using HCGactivated residual dormant follicles in vivo. One patient subsequently gave birth to a healthy baby boy, and another patient became pregnant. In this review, we summarize the potential use of HCG as a new infertility treatment in POI patients.

\section{Patients And Methods}

Four POI patients all presented with amenorrhoea or oligomenorrhoea for at least four months and embarked on intermittent hormone therapy for several years, they were exploring the possibility of pursuing a pregnancy through IVF treatment. The follicles were monitored continuously for 1 year and no follicles were visualized before they were referred to our center. During the first appointment, the detailed reproductive examinations were performed, including the ultrasound reports(Fig 1), the hormone and anti-mullerian hormone(AMH) profiles assessment(Table 1-4). Karyotyping all showed $46 \mathrm{XX}$ chromosomal in four patients. In our center, they were pretreated with dehydroepiandrosterone (DHEA), Coenzyme Q10, estrogen (Progynova, Bayer) and medroxyprogesterone (Dupbaston, Abbott Biologicals B.V) for 3 months, and the ultrasound monitored follicles continuously every 1-2 weeks. The prescribed amounts of estrogen and medroxyprogesterone were adjusted to maintain the level of FSH at $\nabla 15 \mathrm{mIU} / \mathrm{ml}$ and the level of $\mathrm{LH} \otimes 10 \mathrm{mIU} / \mathrm{ml}$. When the treatments failed to induce the appearance of follicles for 30 days, the cycle was cancelled, the medication was stopped and the patients proceeded to the next cycle of medication after menstruation.

In this study where estrogen/medroxyprogesterone treatment lasted for 3 months and no follicles were observed in the bilateral ovaries, then the patient received HCG 10000 IU (Chorionic Gonadotrophin, Livzon) and continued to receive estrogen/progesterone to reduce the levels of endogenous gonadotropin. They also received weekly or biweekly ultrasound examinations. When the diameter of the dominant follicle was $\geq 18 \mathrm{~mm}$ and the Estradiol $\left(\mathrm{E}_{2}\right)$ level was $\geq 150 \mathrm{pg} / \mathrm{ml}$, the egg retrieval was activated with 250IU of rhCG (Recombinant Human Choriogonadotropin alfa solution, Merck Serono S.p.A) and $0.1 \mathrm{ml}$ of Tritorelin Acetate (Ipsen Pharma Biotech). The oocytes were transvaginally collected under ultrasound guidance at $36 \mathrm{~h}$ after triggering and cultured in vitro for 3 days. All embryos were vitrified for cryopreservation. 
Before preparing for frozen embryos transplantation (FET), all patients underwent hysteroscopy and ensured there were no adhesions or polyps in the uterine cavity. In the artificial cycle protocol, the endometrium was prepared with estradiol valerate ( $2 \mathrm{mg}$ three times daily, Estrofem, Novo Nordisk, Turkey) beginning on day 3 of menses. If endometrial thickness was $\geq 7 \mathrm{~mm}$ and the serum $E_{2}$ level was $>150 \mathrm{pg} / \mathrm{mL}$,vaginal progesterone gel (90 mg/day, Progestan, Serono Rome, Italy) was started,the embryos were thawed after using vaginal progesterone gel for 3 days. Two patients transferred D3 embryos, and the other two patients embryos continued culture for 2 days to obtain blastocysts for transplantation. $90 \mathrm{mg}$ of vaginal progesterone gel was used once a day for luteum supplementation after transplantation.

The first patient, aged 31,was diagnosed as being prematurely menopausal at the age of 26. Laboratory findings in Jun 2016 reported FSH levels of $50.23 \mathrm{mlU} / \mathrm{ml}$, LH levels of $13.39 \mathrm{mlU} / \mathrm{ml}$ and $\mathrm{E}_{2}$ levels of 40.09pg/ml. In Aug 2016 laboratory findings reported $\mathrm{FSH}$ levels of $45.75 \mathrm{mlU} / \mathrm{ml}$, LH levels of $12.87 \mathrm{mlU} / \mathrm{ml}$ and $\mathrm{E}_{2}$ levels of $7.00 \mathrm{pg} / \mathrm{ml}$. At 38 days after HCG injection, a $9.5 \mathrm{~mm}$ follicle was observed in the right ovary(Table 1). The patient did not receive an $\mathrm{LH}$ antagonist as the LH levels were low when the follicle from $13.5 \mathrm{~mm}$ to $18.0 \mathrm{~mm}$. Exogenous gonadotropin was not given. One metaphase II oocyte was obtained under ultrasound guidance.

The second patient was 31 years old who presented with oligomenorrhoea since 23. At the age of 26 , she presented with hot flushes, insomnia, dyspareunia, and emotional lability. Laboratory findings in April 2017 showed FSH levels of $85.13 \mathrm{mlU} / \mathrm{ml}$, LH levels of $34.25 \mathrm{mIU} / \mathrm{ml}$ and $\mathrm{E}_{2}$ levels of $18 \mathrm{pg} / \mathrm{ml}$. In Aug 2017 laboratory findings reported FSH levels of $95.65 \mathrm{mIU} / \mathrm{ml}$, LH levels of $29.75 \mathrm{mIU} / \mathrm{ml}$ and $\mathrm{E}_{2}$ levels of $12 \mathrm{pg} / \mathrm{ml}$. At 43 days after HCG injection, a 18.5 $\mathrm{mm}$ follicle presented in the left ovary(Table 2) and a metaphase II oocyte was obtained.

The third patientwas 38 years old who presented with oligomenorrhoea since 30. The laboratory findings in Apr 2013 reported FSH levels of $32.5 \mathrm{mlU} / \mathrm{ml}$, LH levels of $13.5 \mathrm{mlU} / \mathrm{ml}$ and $\mathrm{E}_{2}$ levels of $17.0 \mathrm{pg} / \mathrm{ml}$. In Aug 2013 laboratory findings reported FSH levels of $54.52 \mathrm{mlU} / \mathrm{ml}$, LH levels of $23.52 \mathrm{mlU} / \mathrm{ml}$ and $\mathrm{E}_{2}$ levels of $4.0 \mathrm{pg} / \mathrm{ml}$. The patient presented with hot flashes and insomnia since 2018. At 29 days after the HCG injection, a $14.0 \mathrm{~mm}$ follicle was observed in the left ovary(Table 3). The patient received an LH antagonist(Cetrorelix Acetate, Merck Serono S. pA) for 4 days as the $\mathrm{LH}$ levels were high when the follicle reached a diameter of $14.0 \mathrm{~mm}$. Exogenous gonadotropin was not given. One metaphase II oocyte was obtained under ultrasound guidance.

The fourth patient was a 34 year old who presented with oligomenorrhoea since the age of 29 . The laboratory findings in Oct 2016 reported FSH levels of $66.13 \mathrm{mlU} / \mathrm{ml}$, LH levels of $34.26 \mathrm{mlU} / \mathrm{ml}$ and $\mathrm{E}_{2}$ levels of $19.61 \mathrm{pg} / \mathrm{ml}$. In Feb 2017 laboratory findings reported FSH levels of $76.15 \mathrm{mlU} / \mathrm{ml}$, LH levels of $23.7 \mathrm{mlU} / \mathrm{ml}$ and $\mathrm{E}_{2}$ levels of 38.89 $\mathrm{pg} / \mathrm{ml}$. The patient presented with vaginal dryness, difficulties during intercourse, and developed symptoms of hot flashes, palpitation, insomnia and depression since 2019. At 29 days after the HCG injection, a $16.0 \mathrm{~mm}$ follicle was observed in the left ovary (Table 4). The patient received Cetrorelix Acetate for 4 days as the LH levels were high when the follicle reached a diameter of $16.0 \mathrm{~mm}$. Exogenous gonadotropin was not given. One metaphase II oocyte was obtained under ultrasound guidance.

\section{Results}

For the first patient, an 8C1 embryo was preserved by vitrification (Fig 2). The patient continued estrogen/medroxyprogesterone treatment for 4 months after oocyte collection and B-ultrasound did not detect any antral follicles. She received a 3BB blastocyst transplantation. At 10 days after implantation, the level of $\beta$-HCG was $215.21 \mathrm{mlU} / \mathrm{ml}$, and at 13 days after implantation, the level of $\beta-\mathrm{HCG}$ was $820 \mathrm{mIU} / \mathrm{ml}$. At 24 days after implantation, 
B-ultrasound showed a gemmule and the vitellus bag had a primitive heart tube pulse. At 71 days after implantation, early pregnancy screening reported that the fetal crown-rump length (CRL) was $6.49 \mathrm{~cm}$ and the Nuchal Translucency(NT) was $0.9 \mathrm{~cm}$. Non-invasive Prenatal Testing(NIPT) showed that trisomy of chromosomes 21,18 and 13 were all low-risk (Fig 3).

An 8c1 embryo was vitrified for the second patient (Fig 2). The patient continued estrogen/medroxyprogesterone treatment after oocyte collection and no antral follicles were observed in the ovaries at 87 days after HCG injection. A second injection of HCG10000 IU was required. At 7 months after the injection there were no antral follicles in both ovaries. The couple transferred a 3BB blastocyst. At 10 days after the implantation, the level of $\beta$-HCG was 387.8 $\mathrm{mIU} / \mathrm{ml}$. After 3 days, the $\beta$-HCG level was $2077.00 \mathrm{mlU} / \mathrm{ml}$. At 31 days after the implantation, B-ultrasound detected a gemmule and the vitellus bag had a primitive heart tube pulse. 77 days after implantation, early pregnancy screening showed that the fetal CRL was $7.2 \mathrm{~cm}$ and the NT was $0.12 \mathrm{~cm}$. NIPT showed that trisomy of chromosomes 21,18 and 13 were all low-risk (Fig 4). On April $21^{\text {st }}, 2021$, the patient delivered a 3.65 kg healthy baby boy by cesarean section at term.

For the third patient, an 8C1 embryo was finally obtained and persevered by vitrification (Fig 2). Two months after oocyte collection, the $8 \mathrm{C} 1$ embryo was transferred. At $13 \mathrm{~d}$ after the implantation, the level of $\beta$-HCG was 161.5 $\mathrm{mIU} / \mathrm{ml}$, and at $16 \mathrm{~d}$ after implantation, the level of $\beta-H C G$ was $459.84 \mathrm{mlU} / \mathrm{ml}$. At $22 \mathrm{~d}$ after implantation, the level of $\beta$-HCG was $1362.49 \mathrm{mlU} / \mathrm{ml}$. The patient experienced vaginal bleeding and eventually had a miscarriage. The $B-$ ultrasound examination did not detect any antral follicle for 3 months after the miscarriage. Then she received a 10000 U HCG injection again, with re-injection after 62 days. A $15.5 \mathrm{~mm}$ follicle was observed in the left ovary, the level of $E_{2}$ was $113 \mathrm{pg} / \mathrm{ml}$, the level of $\mathrm{LH}$ was $14.47 \mathrm{mlU} / \mathrm{ml}$, and the level of $\mathrm{FSH}$ was $16.99 \mathrm{mIU} / \mathrm{ml}$. The patient did not receive Cetrorelix Acetate for two days and the follicle ovulated.

For the fourth patient, a 7C1 embryo was finally obtained and preserved by vitrification(Fig 2). She continued to receive estrogen/medroxyprogesterone treatment after oocyte collection. A $5.5 \mathrm{~mm}$ antral follicle in the left ovary was observed at $79 \mathrm{~d}$ after HCG injection. At this time level of $\mathrm{E}_{2}$ was $30 \mathrm{pg} / \mathrm{ml}$, FSH was $7.39 \mathrm{mIU} / \mathrm{ml}$, and LH was $6.27 \mathrm{mIU} / \mathrm{ml}$. 5 days later, the diameter of the antral follicle did not increase and the $\mathrm{E}_{2}$ level was $31 \mathrm{pg} / \mathrm{ml}$, FSH was $7.54 \mathrm{mIU} / \mathrm{ml}$, and LH was $5.84 \mathrm{mIU} / \mathrm{ml}$. The patient received injections of $225 \mathrm{IU} \mathrm{rFSH}$ (Recombinant Human Follitropin Alfa Solution, Merck Serono S. pA) for 8 days, however, the antral follicle disappeared. After 2 months, the patient transferred the 7C1 embryo, but was not pregnant.

\section{Discussion}

Different drug interventions have been recommended to improve ovarian function in POI patients. Androgen potentiates the expression of FSH receptor and supports preantral follicle development in mice(11). DHEA promotes follicular development and granulosa cell proliferation by increasing the androgen levels in the ovaries and it may have a role as a treatment for premature ovarian insufficiency(12). Coenzyme Q10 significantly increases the number of antral follicles in aged mice and effectively improves ovarian reserves and mitochondrial function (13). DHEA combined with Coenzyme Q10 can significantly increase the number of antral follicles and improve the ovarian response (14).

The occurrence (although rare) of a spontaneous pregnancy during cyclic estrogen and progestin therapy(15). It is generally accepted that FSH $>40 \mathrm{IU} / \mathrm{L}$ is associated with sterility and that induction of ovulation in POI patients is ineffective(16). It was hypothesized that the hypergonadotropic condition alone may reduce ovarian responsiveness. Estrogen-induced decrease in serum FSH improves the responsiveness of remnant ovarian follicles by the induction 
of an upregulation of FSH receptors in granulosa cells(17). First in 1996, Taylor showed a spontaneous ovulation in $46 \%$ of POI patients treated with estrogens (18). The four patients in this study did not have any antral follicles with 1 year of continue estrogen and progesterone therapy and the serum levels of FSH remained at a high level at the first visit to our center. In POI patients, Tartagni et al. reported that ovulation is only possible when the level of FSH is $\otimes 15$ IU/L(19). Sara et al. confirmed that ovulation induction was satisfactory only in women whose FSH levels at the beginning of $\mathrm{COH}$ were lower than $15 \mathrm{IU} / \mathrm{L}(17)$. Reducing the levels of $\mathrm{FSH}$ whilst reducing $\mathrm{LH}$ to within the normal range can increase the ovulation rate of POI patients (20). Vaishali et al. reported that the normal range of $\mathrm{LH}$ in $\mathrm{POI}$ patients is 3-14 IU/L (21). High progesterone levels can avoid the appearance of endogenous LH peak (19). Also, Yanping et al. reported that the use of medroxyprogesterone during ovulation induction does not increase the frequency of birth defects in newborns (22).

In this study, after estrogen and medroxyprogesterone treatment for 3 months, no follicles were observed in the bilateral ovaries. The patients did not want to wait for other treatments and so received HCG $10000 \mathrm{U}$. Follicles were detected in the four patients at 29, 38, 43, 62, 79 days after HCG treatment. Under normal conditions, it takes 150 days for human primordial follicles to develop into primary follicles, 120 days for primary follicles to develop into secondary follicles, and 85 days for secondary follicles to develop into mature follicular phase follicles (it takes 60 days to develop from secondary follicles into antral follicles $2 \mathrm{~mm}$ in diameter, and 25 days from antral follicles to develop into mature follicles) (23). We hypothesize that HCG may activate and accelerate the development of immature follicles from dormant follicles which would otherwise remain fixed the stage of secondary follicle development.

The growth of antral follicles is mainly regulated by ovarian regulatory factors and hormones. Epidermal growth factor (EGF) is a key growth factor in the regulation of follicular development and maturation. Growth differentiation factor 9 (GDF-9) and bone morphogenetic protein 15 (BMP-15) are derived from oocytes which play important roles in the development of preantral follicles into antral follicles (24). GDF-9 is expressed in $96 \%$ of human secondary follicles and promotes the expansion of the mouse cumulus $(25,26)$ and the growth of human and goat preantral follicles in vitro $(27,28)$. BMP-15 stimulates the proliferation of granulosa cells $(29)$, regulates the sensitivity of HGC to FSH and increases oocyte development $(30,31)$.

The response of follicles to HCG stimulation is mediated by EGF-like growth factors produced by granulosa cells. HCG binds to the LH receptors in the parietal granulosa cells to rapidly induce the expression of EGF expression and activate EGF receptors in granulosa and cumulus cells through autocrine and paracrine pathways. These changes then further activate the key factors that promote cell proliferation and differentiation through the mitogen-activated protein kinase (MAPK)(32).

MAPK has been shown to stimulate granulosa cell proliferation and induce cumulus expansion and oocytes maturation (33). The effect of HCG on follicles also requires the involvement of oocyte-derived paracrine factors. The LH surge after HCG injection can increase the secretion of GDF-9 and BMP-15 to promote cumulus expansion and oocytes maturation (34). The surge in GDF-9 can also significantly enhance FSH-induced preantral follicles growth in vitro (27). Moreover, according to the two-cell and two-gonadotropin theory, HCG stimulates follicular membrane cells to produce sex hormones. Androgens diffuse to adjacent granulosa cells and are aromatized to estrogen. Aromatization is accelerated with the estrogen microenvironment which depends on FSH stimulation of the granulosa cells. Guelkli et al. found that 10000 IU of HCG increases the maturation rates of oocytes in vitro but higher doses of HCG did not improve the maturation rate of oocytes (35). 


\section{Conclusions}

IVA follicles, ovarian injection and transplantation, and mitochondrial replacement therapy are expensive forms of treatment for $\mathrm{POI}$ patients and their clinical applications require further validation. Currently, there are no convenient, effective and economical treatments that can improve ART outcomes in POI patients. In this study, we report a breakthrough infertility treatment for POI patients that can activate dormant follicles in vivo, and maybe allow them to conceive their own genetic children. However, the mechanism of HCG activation of residual dormant follicles remains unclear and requires mechanistic investigations.

\section{Abbreviations}

Human chorionic gonadotropin (HCG)

Premature ovarian insufficiency(POI)

European Society of Human Reproduction and Embryology (ESHRE)

Follicle-stimulating hormone (FSH)

In vitro activation (IVA)

Platelet-rich plasma (PRP)

Luteinizing hormone (LH)

Anti-mullerian hormone(AMH)

Dehydroepiandrosterone (DHEA)

Estradiol $\left(E_{2}\right)$

Frozen embryos transplantation (FET)

Crown-rump length (CRL)

Nuchal Translucency(NT)

Non-invasive Prenatal Testing(NIPT)

Epidermal growth factor (EGF)

Growth differentiation factor 9 (GDF-9)

Bone morphogenetic protein 15 (BMP-15)

Mitogen-activated protein kinase (MAPK)

\section{Declarations}


This project was approved by the Medical Ethics Committees of The Fourth Affiliated Hospital of Zhejiang University School of Medicine. Written informed consent for publication of clinical details was obtained from individual patients.

\section{Consent for publication}

All data generated or analysed during this study are included in this published article.

\section{Availability of supporting data}

The data sets supporting the results of this article are included within the article and its additional figures and tables.

\section{Competing interests}

The authors declare that they have no competing interests.

\section{Funding}

This project has been funded by the National Key research and developement Program of China(2019YFC0121004) and the Key Project of Jinhua Social Development (2018-3-021).

\section{Authors' contributions}

Xiao Chen, Keda Yu, Hong Liu and Chen Chen wrote the main manuscript text; Yuanyuan Yu, Yingying Hu and Youjiang Li prepared figures1-4 and Tables 1-4; Jian Xu edited the article.All authors read and approved the final manuscript.

\section{Acknowledgments}

The authors would like to acknowledge the contributions of Dr bingbing Wu for revising the manuscript critically for important intellectual content. The authors gratefully acknowledge the financial assistance to our project by the Ministry of Science and Technology of China, Jinhua Social Development Bureau.

\section{References}

1. Kovanci E, Schutt AK. Premature ovarian failure: clinical presentation and treatment. Obstet Gynecol Clin North Am 2015; 42:153-161.

2. Ewa Rudnicka,Jagoda Kruszewska,Klaudia Klicka, Joanna Kowalczyk,Monika Grymowicz,Jolanta Skorska,Wojciech Pieta,Roman Smolarczyk.Premature ovarian insufficiency-aetiopathology, epidemiology, and diagnostic evaluation. Prz Menopauzalny 2018; 17(3): 105-108.

3. Kazuhiro Kawamura,Nanami Kawamura, Aaron J.W. Hsueh . Activation of dormant follicles: a new treatment for premature ovarian failure?.Curr Opin Obstet Gynecol 2016; 28(3): 217-222.

4. Suzuki N, Yoshioka N, Takae S, Sugishita Y, Tamura M, Hashimoto S, Morimoto Y,Kawamura K. Successful fertility preservation following ovarian tissue vitrification in patients with primary ovarian insufficiency. Human reproduction (Oxford, England) 2015;30(3):608-15.

5. Zhai J,Yao G,Dong F,Bu Z,Cheng Y,Sato Y, Hu L,Zhang YY,Wang JY,Dai SY,Li J,Sun J, Hsueh AJ,Kawamura K,Sun YP.In Vitro Activation of Follicles and Fresh Tissue Auto-transplantation in Primary Ovarian Insufficiency Patients. The Journal of clinical endocrinology and metabolism 2016;101(11):4405-12. 
6. Pantos K, Simopoulou M, Pantou A, Rapani A, Tsioulou P,Nitsos N,Syrkos S,Pappas A,Koutsilieris M,Sfakianoudis K. A case series on natural conceptions resulting in ongoing pregnancies in menopausal and prematurely menopausal women following platelet-rich plasma treatment. Cell Transplant 2019;28(9-10):13331340.

7. Yihua Lin, Xiaoying Zheng,Caihong Ma, Xiaoxue Li,Xinyu Zhang, Puyu Yang, Jiayu Xu,Jinliang Zhu. Human Chorionic Gonadotropin Priming Does Not Improve Pregnancy Outcomes of PCOS-IVM Cycles. Front Endocrinol 2020; 11: 279.

8. Son WY, Lee SY, Lim JH. Fertilization, cleavage and blastocyst development according to the maturation timing of oocytes in in vitro maturation cycles. Human reproduction (Oxford, England) 2005;20(11):3204-7.

9. Lin YH, Hwang JL, Huang LW, Mu SC, Seow KM, Chung J,Hsieh BC,Huang SC,Chen CY,Chen PH. Combination of FSH priming and hCG priming for in-vitro maturation of human oocytes. Human reproduction (Oxford, England) 2003;18(8):1632-6.

10. Liu J, Katz E, Garcia JE, Compton G, Baramki TA. Successful in vitro maturation of human oocytes not exposed to human chorionic gonadotropin during ovulation induction, resulting in pregnancy. Fertility and sterility 1997;67(3):566-8.

11. Yuya Fujibe,Tsuyoshi Baba, Sachiko Nagao,Sayaka Adachi,Keiko Ikeda, Miyuki Morishita,Yoshika Kuno,Masahiro Suzuki,Masahito Mizuuchi,Hiroyuki Honnma,Toshiaki Endo,Tsuyoshi Saito. Androgen potentiates the expression of FSH receptor and supports preantral follicle development in mice. J Ovarian Res 2019;12(1):31.

12. A. Narkwichean,K. Jayaprakasan, W.E.Maalouf,J.H.Hernandez-Medrano,C.Pincott-Allen1,B.K. Campbell. Effects of dehydroepiandrosterone on in vivo ovine follicular development.Human Reproduction 2014;29(1):146-154.

13. Assaf Ben-Meir,Eliezer Burstein,Aluet BorregoAlvarez,Jasmine Chong,Ellen Wong,Tetyana Yavorska,Taline Naranian,Maggie Chi,Ying Wang,Yaakov Bentov,Jennifer Alexis,James Meriano,Hoon-Ki Sung,David L. Gasser,Kelle H. Moley,Siegfried Hekimi,Robert F. Casper and Andrea Jurisicova. Coenzyme Q10 restores oocyte mitochondrial function and fertility during reproductive aging.Aging Cell 2015;14:887-895.

14. Gat I, Blanco Mejia S, Balakier H, Librach CL, Claessens A, Ryan EA. The use of coenzyme Q10 and DHEA during IUI and IVF cycles in patients with decreased ovarian failure. Gynecological endocrinology : the official journal of the International Society of Gynecological.Endocrinology 2016;32(7):534-7.

15. Firoozeh Akbari Asbagh M.D.,Mahbod Ebrahimi M.D.A case report of spontaneous pregnancy during hormonal replacement therapy for premature ovarian failure.Iranian Journal of Reproductive Medicine 2011;9(1): 47-49.

16. Anasti JN. Premature ovarian failure: an update. Fertil Steril 1998;70(1):1-15.

17. Sara Pinelli,Paolo Giovanni Artini,Stefano Basile,Maria Elena Rosa Obino,Claudia Sergiampietri,Diana Giannarelli,Giovanna Simi,Vito Cela. A randomized, controlled trial of estradiol replacement therapy in women witEstrogen treatment in infertile women with premature ovarian insufficiency in transitional phase: a retrospective analysis.Journal of Assisted Reproduction and Genetics 2018;35:475-482.

18. Taylor AE, Adams JM, Mulder JE, Martin KA, Sluss PM, Crowley WF. A randomized, controlled trial of estradiol replacement therapy in women with hypergonadotropic amenorrhea. J Clin Endocrinol Metab 1996;81(10):3615-21.

19. Tartagni M, Cicinelli E, De Pergola G, De Salvia MA, Lavopa C, Loverro G. Effects of pretreatment with estrogens on ovarian stimulation with gonadotropins in women with premature ovarian failure:a randomized,placebocontrolled trial.Fertility and sterility 2007;87(4):858-61. 
20. Lin J, Li X L, Song H, Li Q,Wang M Y,Qiu X M,Li D J,Wang L. A general description for Chinese medicine in treating premature ovarian failure. Chin J Integr Med 2017;23(2):91-97.

21. Popat V B, Vanderhoof V H, Calis K A,Troendle J F,Nelson L M.Normalization of serum luteinizing hormone levels in women with 46,XX spontaneous primary ovarian insufficiency.Fertil Steril 2008;89(2):429-433.

22. Kuang Y, Chen Q,Fu Y L,Wang Y,Hong Q Q,Lyu Q F,Ai A,Shoham Z. Medroxyprogesterone acetate is an effective oral alternative for preventing premature luteinizing hormone surges in women undergoing controlled ovarian hyperstimulation for in vitro fertilization.Fertil Steril 2015;104(1):62-70.

23. McGee EA, Hsueh AJ. Initial and cyclic recruitment of ovarian follicles. Endocrine reviews 2000;21(2):200-14.

24. Sun RZ, Lei L, Cheng L, Jin ZF, Zu SJ, Shan ZY,Wang ZD,Zhang JX,Liu ZH.Expression of GDF-9, BMP-15 and their receptors in mammalian ovary follicles.Journal of molecular histology 2010;41(6):325-32.

25. Diaz FJ, Wigglesworth K, Eppig JJ. Oocytes are required for the preantral granulosa cell to cumulus cell transition in mice. Developmental biology 2007;305(1):300-11.

26. Dragovic RA,Ritter LJ,Schulz SJ,Amato F,Armstrong DT,Gilchrist RB. Role of oocyte-secreted growth differentiation factor 9 in the regulation of mouse cumulus expansion. Endocrinology 2005;146(6):2798-806.

27. Hayashi M, McGee EA, Min G, Klein C, Rose UM, van Duin M,Hsueh AJ. Recombinant growth differentiation factor-9 (GDF-9) enhances growth and differentiation of cultured early ovarian follicles. Endocrinology 1999;140(3):1236-44.

28. Martins FS, Celestino JJ, Saraiva MV, Matos MH, Bruno JB, Rocha-Junior CM,Lima-Verda IB,Lucci CM,Bao SN,Figueiredo JR. Growth and differentiation factor-9 stimulates activation of goat primordial follicles in vitro and their progression to secondary follicles.Reproduction, fertility, and development 2008;20(8):916-24.

29. Lucidi P, Bernabo N, Turriani M, Barboni B, Mattioli M.Cumulus cells steroidogenesis is influenced by the degree of oocyte maturation. Reproductive biology and endocrinology : RB\&E 2003;1:45.

30. Chang HM, Qiao J, Leung PC. Oocyte-somatic cell interactions in the human ovary-novel role of bone morphogenetic proteins and growth differentiation factors. Human reproduction update 2016;23(1):1-18.

31. Shimasaki S, Moore RK, Otsuka F, Erickson GF. The bone morphogenetic protein system in mammalian reproduction. Endocrine reviews 2004;25(1):72-101.

32. Jin X, Han CS, Zhang XS, Yuan JX, Hu ZY, Liu YX. Signal transduction of stem cell factor in promoting early follicle development.Molecular and cellular endocrinology 2005;229(1-2):3-10.

33. Li-Ping Z, Da-Lei Z, Jian H, Liang-Quan X, Ai-Xia X, Xiao-Yu D,Dan-Feng T,Yue-Hui Z. Proto-oncogene c-erbB2 initiates rat primordial follicle growth via PKC and MAPK pathways. Reproductive biology and endocrinology:RB\&E 2010;8:66.

34. Behrouzi A, Colazo MG, Ambrose DJ. Alterations in bone morphogenetic protein 15, growth differentiation factor 9, and gene expression in granulosa cells in preovulatory follicles of dairy cows given porcine LH. Theriogenology 2016;85(7):1249-57.

35. Gulekli B, Buckett WM, Chian RC, Child TJ, Abdul-Jalil AK, Tan SL. Randomized, controlled trial of priming with 10,000 IU versus 20,000 IU of human chorionic gonadotropin in women with polycystic ovary syndrome who are undergoing in vitro maturation. Fertility and sterility 2004;82(5):1458-9.

\section{Tables}

Table 1. Hormone levels in the first patient who received HCG therapy. 


\begin{tabular}{|c|c|c|c|c|c|c|c|}
\hline Time & $\begin{array}{l}\text { Dose of } \\
\text { HCG(IU/day) }\end{array}$ & $\begin{array}{l}\text { Size of } \\
\text { follicle(mm) }\end{array}$ & $\begin{array}{l}\text { AMH } \\
(\mathrm{ng} / \mathrm{ml})\end{array}$ & $\begin{array}{l}\text { Hormone } \\
\text { levels }\end{array}$ & & & \\
\hline & & & & $\begin{array}{l}\text { FSH } \\
(\mathrm{mlU} / \mathrm{ml})\end{array}$ & $\begin{array}{l}\text { LH } \\
(\mathrm{mlU} / \mathrm{ml})\end{array}$ & $\begin{array}{l}\text { Oestradiol } \\
(\mathrm{pg} / \mathrm{ml})\end{array}$ & $\begin{array}{l}\text { Progesterone } \\
(\mathrm{ng} / \mathrm{ml})\end{array}$ \\
\hline 2018.12.12 & & & 0.02 & 64.83 & 22.33 & 8.00 & 0.31 \\
\hline 2019.03 .30 & 10000 & & & 14.13 & 8.01 & 30.00 & 0.30 \\
\hline 2019.04.10 & & & & 44.53 & 12.60 & 6.00 & 0.01 \\
\hline 2019.04 .16 & & & & 51.02 & 14.80 & 11.00 & 0.00 \\
\hline 2019.04 .25 & & & & 21.97 & 12.14 & 49.00 & 0.00 \\
\hline 2019.05 .06 & & 9.50 & & 12.98 & 6.91 & 107.40 & 0.10 \\
\hline 2019.05 .09 & & 13.50 & & 10.11 & 6.19 & 128.64 & 0.10 \\
\hline 2019.05.12 & & 15.50 & & 9.43 & 6.60 & 174.58 & 0.20 \\
\hline 2019.05 .15 & & 18.00 & & 6.32 & 5.79 & 219.00 & 0.30 \\
\hline
\end{tabular}

Table 2. Hormone levels in the second patient who received HCG therapy.

\begin{tabular}{|llllllll|}
\hline Time & $\begin{array}{l}\text { Dose of } \\
\text { HCG(IU/day) }\end{array}$ & $\begin{array}{l}\text { Size of } \\
\text { follicle(mm) }\end{array}$ & $\begin{array}{l}\text { AMH } \\
(\mathrm{ng} / \mathrm{ml})\end{array}$ & $\begin{array}{l}\text { Hormone } \\
\text { levels }\end{array}$ & & & \\
\hline 219.05 .11 & & & $\begin{array}{l}\text { FSH } \\
(\mathrm{mlU} / \mathrm{ml})\end{array}$ & $\begin{array}{l}\mathrm{LH} \\
(\mathrm{mlU} / \mathrm{ml})\end{array}$ & $\begin{array}{l}\text { Oestradiol } \\
(\mathrm{pg} / \mathrm{ml})\end{array}$ & $\begin{array}{l}\text { Progesterone } \\
(\mathrm{ng} / \mathrm{ml})\end{array}$ \\
\hline 2019.08 .29 & 10000 & & 0.01 & 32.20 & 21.91 & 50.00 & 0.02 \\
\hline 2019.09 .12 & & & 12.69 & 6.89 & 97.00 & 0.02 \\
\hline 2019.09 .26 & & 10.79 & 5.60 & 92.00 & 0.01 \\
\hline 2019.10 .10 & 18.50 & & 4.84 & 5.51 & 95.00 & 0.01 \\
\hline
\end{tabular}

Table 3. Hormone levels in the third patient who received HCG therapy. 


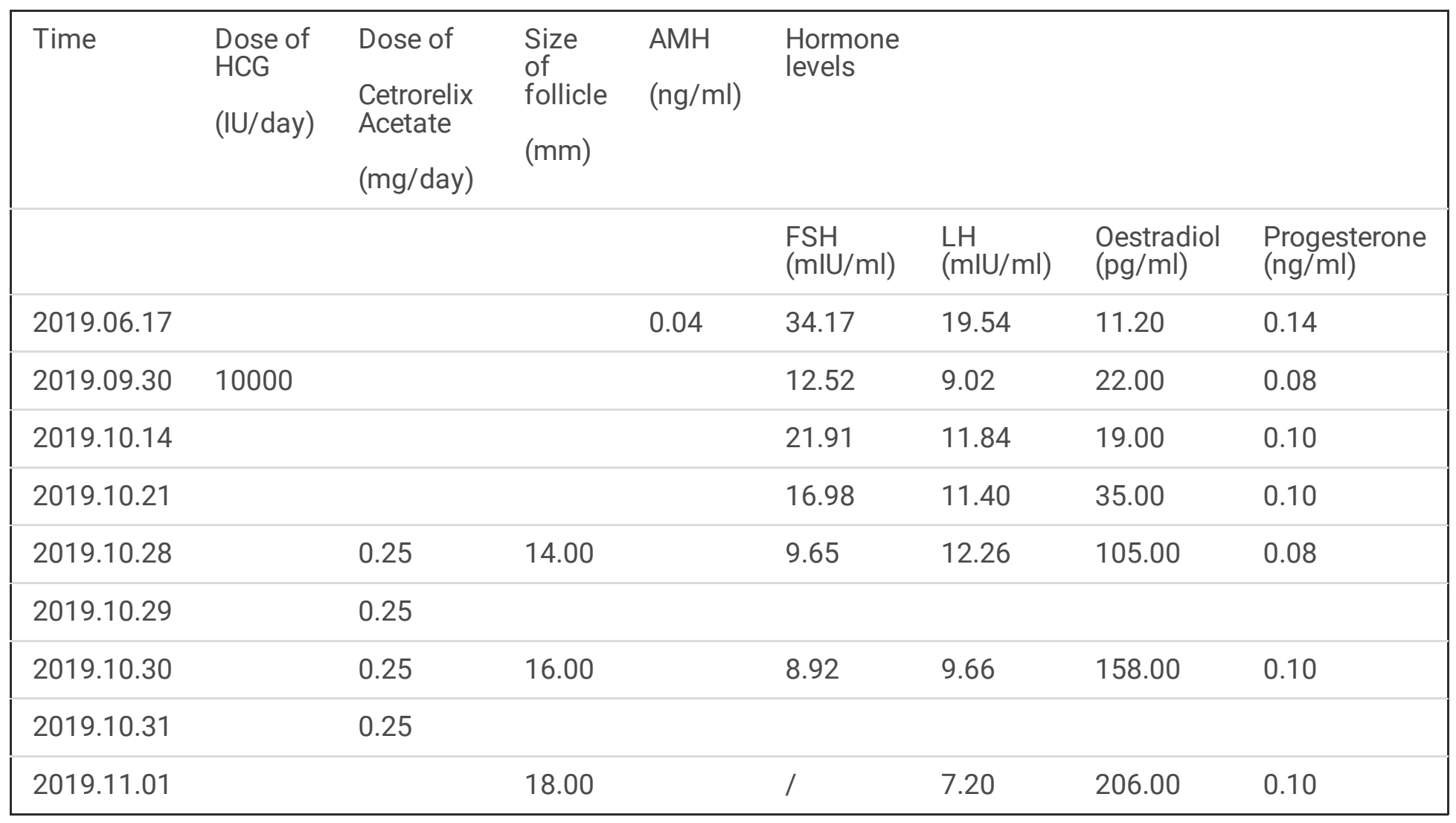

Table 4. Hormone levels in the fourth patient who received HCG therapy.

\begin{tabular}{|c|c|c|c|c|c|c|c|c|}
\hline \multirow[t]{2}{*}{ Time } & \multirow{2}{*}{$\begin{array}{l}\text { Dose of } \\
\text { HCG } \\
(I U / \text { day })\end{array}$} & \multirow{2}{*}{$\begin{array}{l}\text { Dose of } \\
\text { Cetrorelix } \\
\text { Acetate } \\
\text { (mg/day) }\end{array}$} & \multirow{2}{*}{$\begin{array}{l}\text { Size of } \\
\text { follicle } \\
(\mathrm{mm})\end{array}$} & \multirow{2}{*}{$\begin{array}{l}\text { AMH } \\
(\mathrm{ng} / \mathrm{ml})\end{array}$} & $\begin{array}{l}\text { Hormone } \\
\text { levels }\end{array}$ & & & \\
\hline & & & & & $\begin{array}{l}\text { FSH } \\
(\mathrm{mlU} / \mathrm{ml})\end{array}$ & $\begin{array}{l}\mathrm{LH} \\
(\mathrm{mlU} / \mathrm{ml})\end{array}$ & $\begin{array}{l}\text { Oestradiol } \\
\text { (pg/ml) }\end{array}$ & $\begin{array}{l}\text { Progesterone } \\
(\mathrm{ng} / \mathrm{ml})\end{array}$ \\
\hline 2020.04 .11 & & & & 0.02 & 50.60 & 22.72 & 35.42 & 0.17 \\
\hline 2020.07 .30 & 10000 & & & & 14.47 & 8.71 & 56.00 & 0.06 \\
\hline 2020.08.12 & & & & & 46.31 & 18.40 & 19.00 & 0.09 \\
\hline 2020.08.19 & & & & & 35.97 & 17.72 & 35.00 & 0.09 \\
\hline 2020.08.27 & & 0.25 & 16.00 & & 18.89 & 15.02 & 105.00 & 0.06 \\
\hline 2020.08 .28 & & 0.25 & 16.50 & & / & 11.46 & 127.00 & 0.06 \\
\hline 2020.08.29 & & 0.25 & 17.00 & & I & 7.68 & 145.00 & 0.06 \\
\hline 2020.08.30 & & 0.25 & & & & & & \\
\hline 2020.08 .31 & & & 18.00 & & / & 6.03 & 198.00 & 0.09 \\
\hline
\end{tabular}



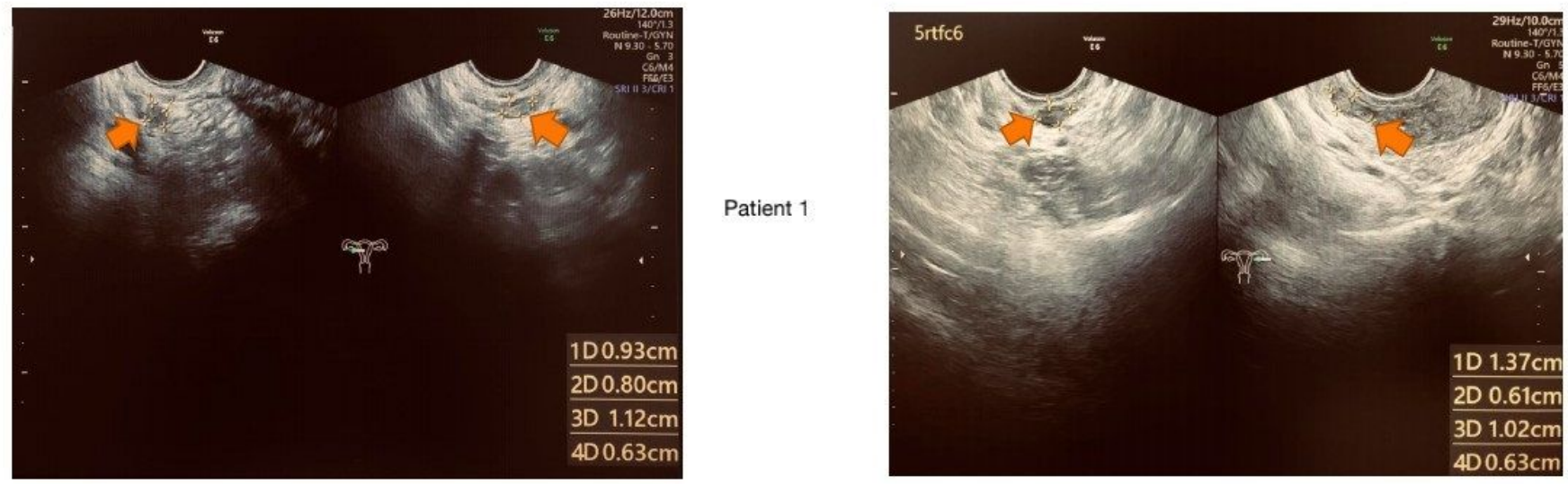

Patient 3
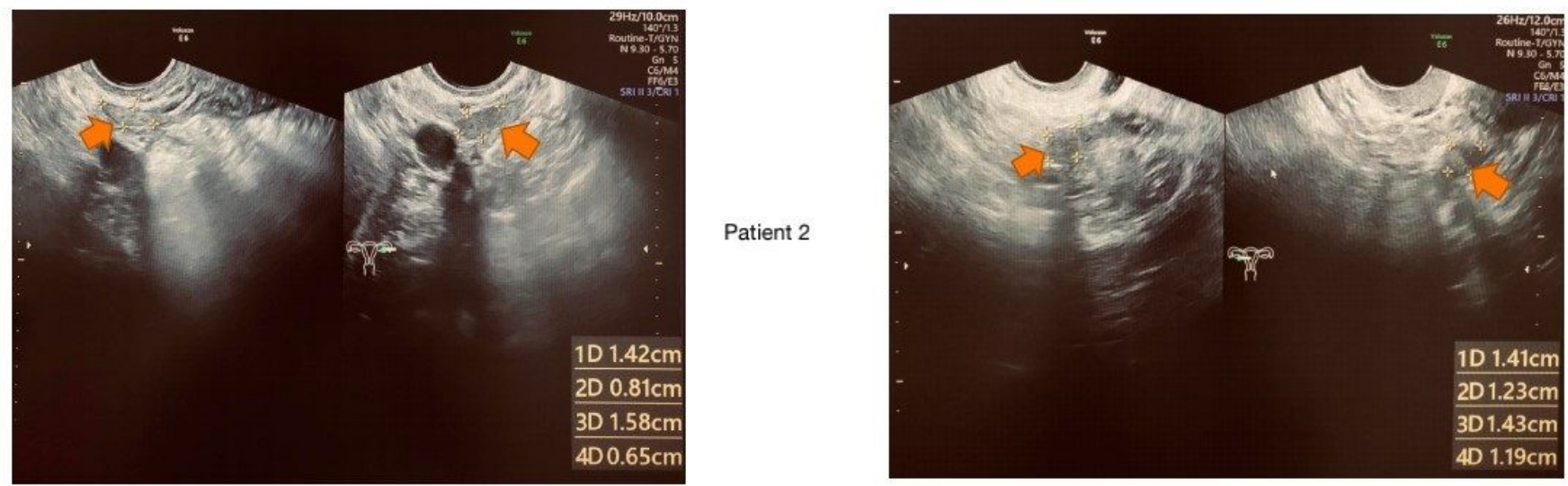

Patient 4

Figure 1

B-ultrasound examination of the four patients(The orange arrows point to the ovaries). 
Day 1
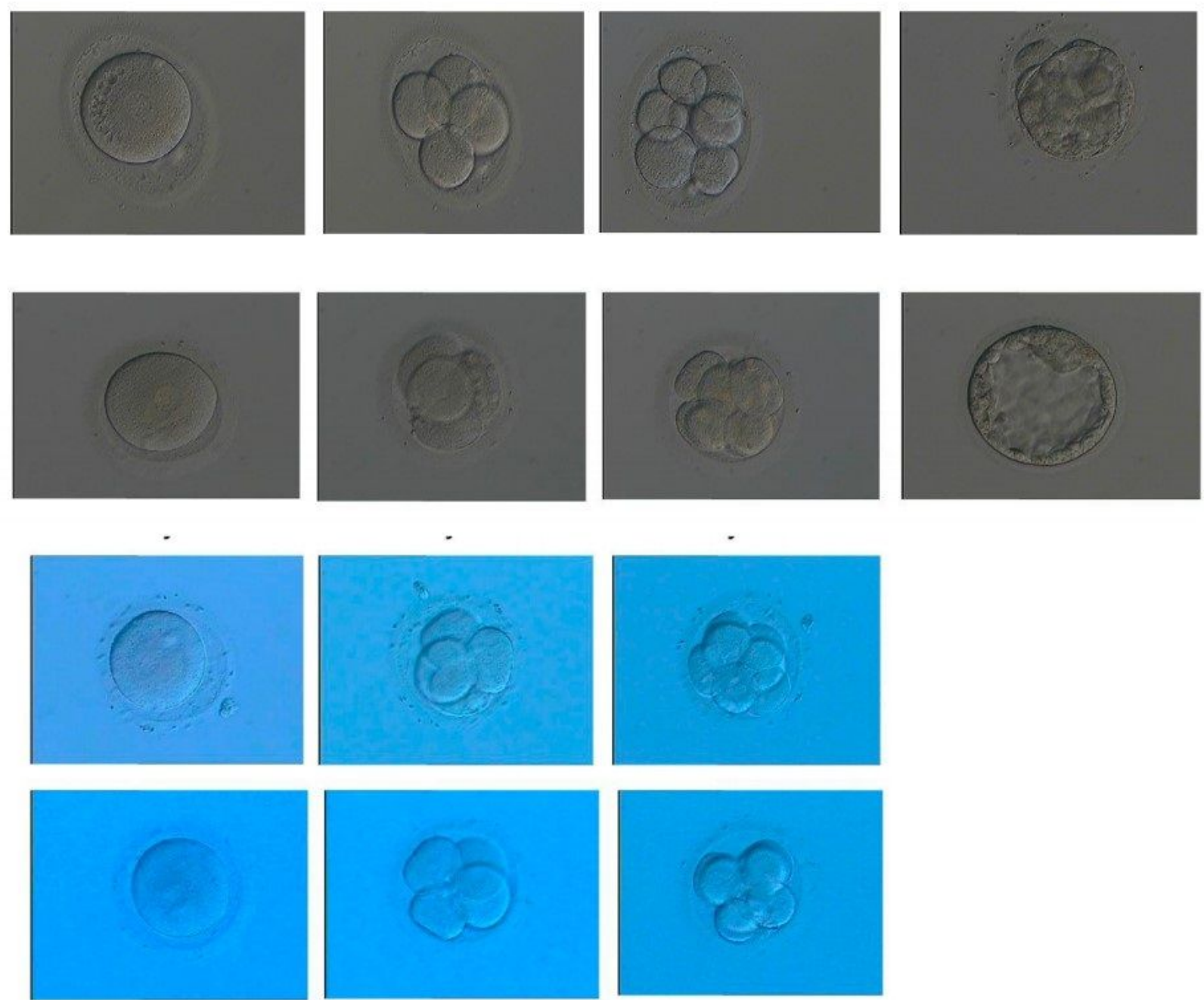

Patient 1

Patient 2

Patient 3

Patient 4

\section{Figure 2}

Imaging of the embryos and blastocysts in the four patients. 

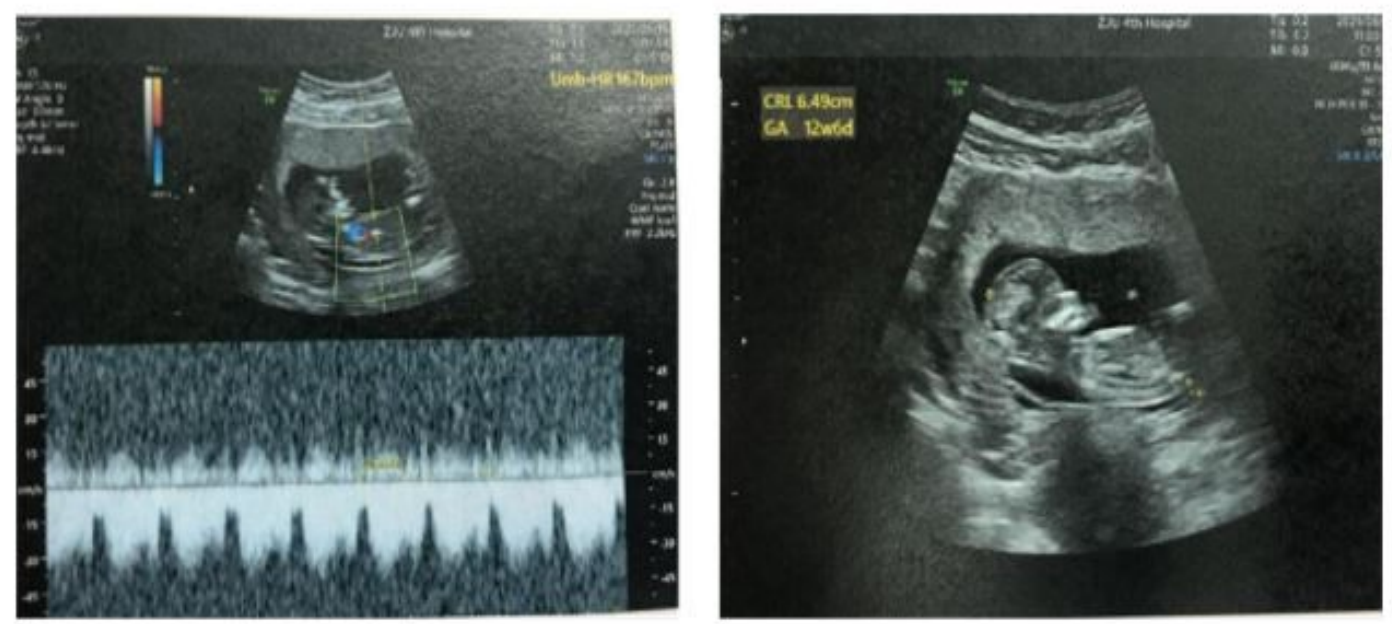

\begin{tabular}{|c|c|c|c|}
\hline Screening Project & Detection Value & Normal Value & Result \\
\hline Trisomy of chromosome 21 & 0.61 & $-0.3-3.0$ & Low-risk \\
\hline Trisomy of chromosome 18 & 1.11 & $-0.3-3.0$ & Low-risk \\
\hline Trisomy of chromosome 13 & -1.16 & $-0.3-3.0$ & Low-risk \\
\hline
\end{tabular}

Figure 3

Imaging of the early pregnancy screening (NT and NIPT results) for the first patient.
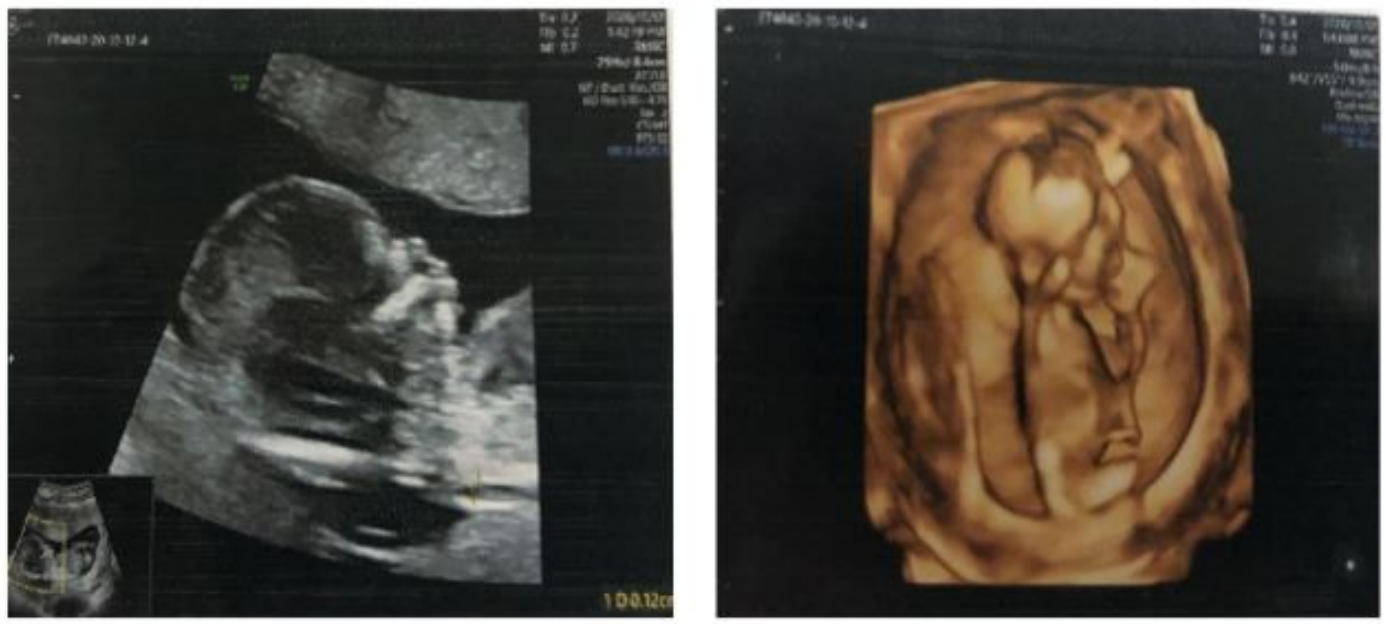

\begin{tabular}{|l|c|c|c|}
\hline Screening Project & Detection Value & Normal Value & Result \\
\hline Trisomy of chromosome 21 & 0.09 & $-0.3-3.0$ & Low-risk \\
\hline Trisomy of chromosome 18 & 0.53 & $-0.3-3.0$ & Low-risk \\
\hline Trisomy of chromosome 13 & -0.66 & $-0.3-3.0$ & Low-risk \\
\hline
\end{tabular}

Figure 4 
Imaging of early pregnancy screening (NT and NIPT results) for the second patient. 